\title{
AC 2007-3023: MORE FEMALES THAN MALES? DECIPHERING THE PSYCHOSOCIAL CHARACTERISTICS THAT ATTRACT GIRLS INTO ENGINEERING IN PUERTO RICO
}

\section{Carmen Maldonado, University of Puerto Rico-Mayaguez}

Carmen Maldonado is a 5th year Industrial Engineering student at the UPRM participating in an undergraduate research opportunities program related to engineering education. Carmen is member of the Institute of Industrial Engineers student chapter and INFORMS.

\section{Tatiana Ramirez, University of Puerto Rico-Mayaguez}

Tatiana Ramirez is in her senior year in Industrial Engineering at the UPRM participating in an undergraduate research opportunities program related to engineering education. Tatiana is member of the Institute of Industrial Engineers student chapter and INFORMS.

\section{Idalis Vazques, University of Puerto Rico-Mayaguez}

Idalis Vazques is in her senior year in Industrial Engineering at the UPRM participating in an undergraduate research opportunities program related to engineering education. Idalis is member of the Institute of Industrial Engineers student chapter and INFORMS.

\section{Alexandra Medina-Borja, University of Puerto Rico-Mayaguez}

Dr. Alexandra Medina-Borja is an assistant professor at the University of Puerto Rico at Mayaguez and Director of the International Service Systems Engineering Lab. Alexandra holds a Masters and Ph.D. degrees from Virginia Tech in Industrial and Systems Engineering and a BS in Production of Materials Engineering from the Federal University of Sao Carlos, in Sao Paulo, Brazil. Her research interests are systems thinking, system dynamics, service operations, performance measurement using DEA, evaluating success factors in engineering and understanding the cognitive processes that occur during their acquisition. 


\title{
More females than males? Deciphering the psycho-social characteristics that attract girls into engineering in Puerto Rico
}

\begin{abstract}
It is broadly recognized that in many industrialized countries there is a gap in the number of applications and enrollments into engineering careers of female students as compared to their male counterparts. The latest statistics in the US talk of a $60 \%$ gap (i.e. $20 \%$ vs $80 \%$ female and male enrollments respectively). Curiously enough, Puerto Rico is the one location in the Western world where a very rigorous 5-year engineering school attracts roughly the same female and male enrollments to any engineering area, and significantly more females than males to Industrial Engineering in particular. While attrition and retention issues continue to be similar to those in other parts of the United States, the University of Puerto Rico at Mayaguiez still graduates more females than males basically due to the initial enrollment numbers. Prior studies about the UPRM case have concentrated in retention strategies and female problems but to our knowledge, no one has tried to determine the psycho-social characteristics of Puerto Rican females that influence their choice of a career in engineering. We present the results of a series of focus groups being undertaken to elicit the factors that affect attraction and retention to the Industrial Engineering program at the UPRM. In this paper, we will concentrate in differentiating prior research findings related to why women are reluctant to enter STEM careers in the US as opposed to in Puerto Rico.
\end{abstract}

\section{Introduction}

It is broadly recognized that in many industrialized countries there is a gap in the number of applications and enrollments into engineering careers of female students as compared to their male counterparts. The latest statistics in the United States talk of a $60 \%$ gap (i.e. $20 \%$ vs. $80 \%$ female and male enrollments respectively). Currently, about ten percent of America's engineers are women, despite the fact that women make up 46 percent of the nation's workforce ${ }^{1}$. And this scenario is not likely to change soon. According to the Extraordinary Women Engineers Project (EWEP) study released in April $2005^{2}$, a staggering number of high school girls - more than 90 percent - do not even consider engineering as a career option. Further, only three out of 85 girls in a EWEP online focus group of academically prepared students indicated that they were planning to become an engineer. According to EWEP, ability is not the issue on the part of girls and young women. Previous studies have found that girls, on average, are just as or more likely as boys to have taken the high school science and math courses (biology, chemistry, physics, and advanced algebra) necessary to enter engineering school.

Curiously enough, Puerto Rico is the one location in the Western world where a very rigorous 5year engineering school, the University of Puerto Rico at Mayaguez, UPRM, attracts roughly $40 \%$ to any engineering area and significantly more females than males to Industrial Engineering (IE) in particular. While attrition and retention issues continue to be similar to those in other parts of the United States, the University of Puerto Rico at Mayaguez still graduates more females than males in IE (60\% to $40 \%$ respectively) basically due to the initial enrollment numbers. Prior studies about the UPRM case have concentrated in retention strategies and female 
problems but to our knowledge, no one has tried to determine the psycho-social characteristics of Puerto Rican females that influence their choice of a career in engineering.

In this paper we present the results of a series of focus groups being undertaken to elicit the factors that influence attraction and retention of female high school students to the Industrial Engineering program at the UPRM. We concentrate on differentiating prior research findings related to perceptions and beliefs of female high school students whom expressed reluctance to enter STEM careers in the US. We compare those findings with what we found in female students at the UPRM. We hope that understanding the environment and attitudes of girls who massively chose engineering will be a step towards facilitating a discussion regarding negative environments, stereotypes and lack of support for engineering and science careers for women in the continental US.

The paper is divided as follows: First we will describe the UPRM and its engineering school providing information regarding admission procedures and the profile of applicants; second, we will review the literature regarding female characteristics and societal perception of the choice of engineering as a career for girls. Third, we will describe the methodology used, findings and last we will provide conclusions and recommendations for future research in this fascinating topic.

\section{The School of Engineering at the UPRM}

The University of Puerto Rico has 11 campuses. The UPRM campus is located on the westernmost part of the Island and is the only one in the public university system where Bachelor of Science degrees in engineering are offered. Puerto Rico is a Commonwealth of the United States and Puerto Ricans are US citizens by birth.

In 2006 the UPRM graduated 606 engineers. Ranked by engineering undergraduate enrollment numbers in 2006 UPRM is the $13^{\text {th }}$ largest US engineering school with 4,521 enrollees. Purdue University ranked number 1 with 6,049 students $^{3}$. UPRM ranks number one in the degrees granted to Hispanics. The second place in number of degrees granted to Hispanics was given to the Polytechnic University of Puerto Rico (a private institution) and the third place belonged to Florida International University with 136 bachelor's degrees awarded ${ }^{4}$.

In 2006 nearly $39 \%$ of the BS degrees in engineering at the UPRM were granted to women. This high percentage varies a lot across engineering disciplines at the UPRM. Chemical Engineering is the area of engineering specialization that granted most degrees to women (nearly $65 \%$ of them) and mechanical engineering the area with fewer (approximately $18 \%$ of their graduates were female). The Industrial Engineering program at the UPRM ranks second in the percentage of female graduates, with $60 \%$ of BS degrees granted to females in 2006. This is an increase of almost $5 \%$ in the last 15 years (55\% of degrees were granted to females in industrial engineering in 1991) ${ }^{5}$. In any case, graduating more female students than males is a unique case for a coed institution and a special case for a minority institution as well.

It is safe to say that most of the female Hispanic engineers in the US come from the UPRM. While 8 percent of all SAT test-takers in the U.S. mentioned engineering as the intended college major in 1999, Puerto Rico's figure is higher, at 12 percent. A comparable figure is not available 
for Hispanic Americans, but the Center for the Advancement of Hispanic in Science and Engineering Education (CASHEE) mentions that less than $3.15 \%$ of college-freshman-age Hispanic Americans enters science and engineering programs at four-year institutions, numbers around 5.1 percent of freshmen intending to major in engineering as being Hispanics ${ }^{6}$.

The Society of Hispanic Professional Engineers cautions against comparisons regarding attitudes and beliefs between Puerto Rico-based Hispanics and stateside Latinos, mainly because the first group does not face language and racial barriers. They are a majority in their land and are benefited by unique factors regarding education and tuition in the island. In fact, beginning in the 1960s, more than in other place in the US or in Latin America there has been a growing emphasis on educational attainment to secure better earnings in Puerto Rico. Strong demand from the local market and the continental U.S. for engineers, coupled with the proliferation of colleges, low tuition costs, and generous student aid, have eased the way for high school students into engineering. However, it is important to say that while tuition incentives are generous in Puerto Rico, housing cost is still a problem for many students. Mayaguiez is far a way from most large urban centers in the island and students cannot commute in most cases. Either parents provide financial help or students have part time jobs in school and in surrounding businesses to pay for their lodging.

\section{Status of the UPRM's College of Engineering in the island}

The UPRM is a highly recognized university in Puerto Rico. Its image comes from being one of the best universities specialized in Engineering and Science in the Caribbean. Engineering graduates get very competitive job offers from the many pharmaceutical, bio-technology and electronics companies in the island ${ }^{7}$. Having a positive image of the career and university setting is one of the recognized attraction factors into STEM careers. Graduate school is also an option as all engineering specialties have well-established graduate programs and many prestigious engineering schools in the continental US come to recruit students, offering full scholarships to the most qualified graduates. Besides, large companies and consulting firms in the US participate in the annual job fair by the hundreds, in search for qualified Hispanic engineers. Research wise, three fourths of its faculty has Ph.D. degrees from the most prestigious American and European engineering schools. The UPRM has a research-oriented culture that resonates in Puerto Rican society due to a history of academic success, having had nine NSF's CAREER awardees in the last ten years among its engineering junior faculty. Several department heads and deans of engineering in universities in the continental US are UPRM graduates.

The role of women professors is also a highlight at the UPRM and particularly in IE. Sixty percent $(60 \%)$ of Industrial Engineering tenure-track faculty are female professors. Thirty three percent $(33 \%)$ of tenured full professors are females, all of them with Ph.D.s.

Nonetheless, none of the above characteristics is unique to the UPRM and it does not help explain alone the number of female applications. The most prestigious engineering schools in the continental US do not get as many female applicants as the UPRM. We will describe few aspects of admissions to understand better who these female engineering graduates are. 


\section{Description of Admission Criteria}

The admission index, called the IGS, is composed of the high school grade point average, the verbal aptitude test score and the mathematics aptitude test score from the College Board Entrance Examination. The highest possible value of the IGS is 4.00 . The weight of the high school GPA is $50 \%$, while the weight for each of the two aptitude tests is $25 \%$ each. Applicants have to declare their major at the time of application in Puerto Rico.

The values of the admissions index to engineering are relatively high. For the engineering class of 2004-2005, the minimum IGS fluctuated from 3.13 for Surveying to 3.42 for Computer Engineering. Consistently, the female admissions IGS has been slightly higher and with a tighter distribution than that of males ${ }^{8}$. The median of the IGS are higher for students applying from private schools as opposed to public school students. These statistics translate in that at the UPRM only the top tier of high school graduates is granted admission in engineering every year.

Regarding economic status of students, around twenty percent of the student body in the college of engineering reported family income in the highest bracket while no less than forty five percent $(45 \%)$ could be categorized by income in the low brackets of society ${ }^{9,10}$.

\section{Methodology}

Focus groups have been used in the past to evaluate engineering programs and to elicit student characteristics [e.g. ${ }^{11}$ ] . The design of the study was based in the seminal work of Richard Krueger's book, Focus Groups: A Practical Guide for Applied Research ${ }^{12}$. Design, execution, and analysis of the study took place over one academic (fall) semester, follow-up reporting took place over the following two months in the spring.

Based on the research objectives and target audience, the research advisor and moderator students determined the types of groups needed. Moderators were previously selected from Industrial Engineering students enrolled in third to fifth year and who are participating in an undergraduate research opportunities program in the IE department. They were instructed in focus groups techniques as described in ${ }^{11}$ and 12 and were instrumental in the development of the script. They conducted several design meetings with their research advisor and developed the script for the focus groups based on the literature, discussions regarding Puerto Rican student culture and other important issues. They established the themes, questions and time table activities.

Potential focus group participants were asked to complete a questionnaire regarding demographic and high school related factors, such as the type of high school they attended, the language of instruction (English or Spanish or bilingual), year of admission to UPRM and expected year of graduation. Other questions regarding their level of math and English in preparatory courses in the first semester were included. The selection was made by these questionnaires. 
Homogeneity within the groups was established as a necessary feature of focus groups and it was obtained based on further classifying the participants into the ten demographic characteristics of them and their schools of origin as follows:

- Gender (male and female),

- Outside experiences (Internship and Coop),

- Type of school (Public and private),

- School language focus (English only, mostly Spanish and bilingual),

- Transfer (Reassigned from other campuses in the UPR system),

- Area (Metropolitan area or rural),

- Pre-basic (Preparatory courses were required prior to Calculus I),

- Academic difficulties (Students who expressed that they will take more than six years until graduation),

- Five years group (students who expressed that they will take exactly five years for graduation) and

- Class level (freshmen or second to fifth year students).

One important development during the design phase was that the research advisor wanted to separate males and female participants in control groups. The moderators, 15 undergraduate students, of which four were males and eleven were female, strongly suggested not doing that, since Puerto Rican youth performs better and feels freer to talk if the group has a mixture of males and females. Both male moderators and female moderators shared the same views. Apparently Puerto Rican boys and girls enjoy being together in discussions and share most other activities and do not have concern of expressing views in front of the opposite sex. Moderators even mention that if the gender were to be separate, we would have problems attracting participants. Nobody was opposed to these views and as a result we controlled this characteristic by giving the recorder the task of identifying in a column with $\mathrm{F}$ or $\mathrm{M}$ when the voice heard in the tapes was that of a female or male. Also, at one point index cards were distributed for them to write certain opinions or emotions, and the cards were colored-coded to identify comments from males and females.

After the arrangement of these features nine types of homogeneous groups were formed controlling for the above characteristics. Forty five students participated in this project. Twenty three were females and twenty two males, all of them were undergraduate students ranging from the freshmen to the fifth-plus year.

One focus group session were executed for each of the twelve types of groups. Pizza was the incentive to attract students for meetings. For each group session, a moderator and a recorder were assigned. No individual names were said during the recording process.

Participants pick up the informed consent form at the door and the focus group began by one of the moderators reading and explaining its content.

Once all sessions finished, a transcription of the tapes was made and became the basis for data analysis.

Questionnaire topics were divided in seven parts: 
- Opening Question, what impacted students the most when they enter in college.

- High School Gap, Academic preparation to face engineering studies.

- Internal and External Motivation, factors that influence decision making process of choosing industrial Engineering as a career.

- Academic life at UPRM, Description made by students about themselves and their experiences at the University.

- UPRM Gap, Teaching strategies whether they are effective or not.

- Industrial Engineering Knowledge, students' perception about Industrial Engineering.

- Future Vision, working as an Industrial Engineering shortly after graduation.

Each topic was assigned to a group of students for further analysis and reporting. A different paper was written based on each topic and findings.

Table 1 shows the questions in the focus group script related to female roles. 
Table 1

\begin{tabular}{|c|c|}
\hline Factor & Questions Asked \\
\hline \multirow{2}{*}{$\begin{array}{l}\text { Dreaming to get } \\
\text { admission to } \\
\text { engineering }\end{array}$} & Did you think you were going to be admitted in the UPRM? \\
\hline & Did people talk about the UPRM when you were in High School? \\
\hline \multirow{2}{*}{ Self-efficacy beliefs } & Did you have any doubts about completing the application \\
\hline & Do you think you were good in math? \\
\hline \multirow{4}{*}{$\begin{array}{l}\text { Cultural biases and } \\
\text { fear of discrimination }\end{array}$} & $\begin{array}{c}\text { What came to your mind when you completed your college } \\
\text { application? }\end{array}$ \\
\hline & In which IE specialty area you see yourself working? \\
\hline & $\begin{array}{c}\text { Did your parents put pressure on you regarding your college } \\
\text { decision? }\end{array}$ \\
\hline & $\begin{array}{c}\text { Did any friend or relative ever tell you that women are not good for } \\
\text { working in industry or with technical jobs? }\end{array}$ \\
\hline \multirow{4}{*}{ Lookout to the future } & Do you think you are going to graduate? \\
\hline & Where do you see yourself working in 10 years? \\
\hline & Do you see yourself working as an IE? \\
\hline & $\begin{array}{l}\text { How much time do you think it would take you to complete the B.S. } \\
\text { in IE? }\end{array}$ \\
\hline
\end{tabular}




\section{Literature Review}

During years the percentage of women that expressed interest in sciences and engineering studies was half of the number of males maintaining this interest. In the United States however, this percentage has been declining. According to these statistics, by the end of high school only $29 \%$ of girls think they would enjoy being a scientist while $52 \%$ of boys think this way ${ }^{13}$. At the end of their first year of college less than $33.33 \%$ of the girls interested in those careers stayed this way $^{12}$. In 2001 Melymuka $^{15}$ reported that even though teenage girls are using computers and the Internet at rates similar to their male peers, they are five times less likely to consider a technology-related career or plan on taking post-secondary technology classes. Researches speculate that this low rate of interest could be due to the views that people have of engineering in the US. In the late 1980s some proposed that boys are socialized to be independent and selfsufficient, competitive, and objective thinkers and girls are not ${ }^{16,17}$. Some studies established that independently from gender discrimination, a reason for which women's participation in highly paid executive positions and in the professorial ranks of academic science and engineering is low relative to the proportion of women in the labor force is because women do not like competition. The competitive nature of the engineering and science curricula reflects masculine characteristics such as independence, detachment, and self-reliance ${ }^{18,19}$. In the $1990 \mathrm{~s}$ a study demonstrated that there was "large gender differences in the propensity to choose competitive environments". Women dislike being in a competitive environment and are less optimistic than men about their competitive ability ${ }^{20}$. Competition can cause fear and anxiety in women because success in a competitive environment can have negative consequences ${ }^{21}$, such as social rejection and loss of femininity ${ }^{22}$. Also women dislike risks ${ }^{23}$.

The lack of academic ability is not necessarily the reason for which women do not study engineering. The literature provides other reasons for which women do not study engineering associated with issues of competition, isolation and lack of female role models ${ }^{24}$. In the words of Betty Shanahan, chief executive officer of the Society of Women Engineers (SWE), "there's plenty of engineering talent among women, but so too are there barriers to projecting it in a male-dominated culture" ${ }^{25}$. Also the lack of women in engineering can be attributed to cultural influences, gender stereotyping at home and in school, peer pressure and images in the media ${ }^{26}$. Books and media perpetuate the image of engineers or scientists as men. In magazines female scientists are featured as "atypical scientists and atypical women." Stereotypes can be on of the reasons for which women are discouraged from pursuing technological careers ${ }^{27}$. Women in science textbooks and among university engineering faculty in 1995 were only $5.5 \%{ }^{28}$. Thus beyond the amount of competition required in engineering, image, stereotyping and fear of rejection are possible factors explaining why there are fewer women than men in this field in the United States.

However, in some places engineering is beginning to attract more women ${ }^{29}$. It has been found in some studies that in general women that study engineering found competition to be enjoyable, felt it promotes learning, and helps encourage collegial relationship. They did not feel that the culture in their programs was overly oppressive in this regard. They did indicate that they had to learn to compete successfully and, that if they did, they would be respected. This was true 
despite their age, marital status, ethnicity, enrollment status, and whether or not they had a female advisor ${ }^{30}$. Changes in society view towards women in the twenty first century may be the possible causes for this increment of women interested in engineering. Today more families experience having both parents working. More male roles are being invaded by working women. However this is just the beginning of female development and yet, women do not have hundred percent of acceptance in the working society. Women in engineering technology programs are satisfied with the level of competition in their programs, but they would like to have more support from faculty and peers, be included more, and be recognized for their abilities ${ }^{31}$.

\section{Results}

We have categorized the results that appeared in the focus groups related to major themes around female students' attraction to engineering in three big categories of psychological and sociological aspects.

- Early dreams, image and aspirations and knowledge of the engineering career in High School

- Self-efficacy beliefs and

- Their current lookout to the future

Table 2 shows some of the representative comments in each category.

\section{Table 2}

\section{Table 3}

\begin{tabular}{|c|c|}
\hline Theme & Commentaries \\
\hline \multirow{2}{*}{$\begin{array}{l}\text { Dreaming to get admission to } \\
\text { engineering }\end{array}$} & $\begin{array}{c}\text { I was sure I was going to enter the UPRM because I had good } \\
\text { grades, my parents' support, my school advisor was excellent } \\
\text { she help us and gave us orientation. }\end{array}$ \\
\hline & My Math teacher motivated us and gave us support. \\
\hline \multirow{3}{*}{ Self-efficacy beliefs } & $\begin{array}{c}\text { I got exited. I'm going to be an engineer and everything is } \\
\text { going to change! because when I get into the UPRM } \\
\text { everything is going to change. }\end{array}$ \\
\hline & $\begin{array}{l}\text { I did not have any doubts. I didn't think about regretting my } \\
\text { decision. }\end{array}$ \\
\hline & $\begin{array}{c}\text { Really, I didn't have an A, but I was good in Mathematics, I } \\
\text { learned a lot. }\end{array}$ \\
\hline
\end{tabular}


I thought I will be a professional. It is not easy to be a woman engineering. It is a challenge you are competing to stand out in an area where most people are used to see men and I see it like a challenge. I say I will be an engineer because I want to be one and that is it. I filled the form quickly because I had the motivation that it was a challenge and I wanted to see if I could fulfill.

Cultural biases and fear of discrimination before entering engineering
Doubts. Not at all. (100\% Female participants)

Well, I like a lot Production, I like Quality Control but if I can go growing in the company and reach administration I will not complain.

I did not feel pressure they simply gave me the liberty to take my decision, obviously they were happy.

Not about industrial engineering but about Civil engineering

Becoming an IE? Yes, I hope so

Maybe ( I will work )in a company with an important position.

Lookout to the future Working as an IE
Sure. I studied for it

Five and a half years or six years.

If I do a COOP I think that I can finish in five and a half years or maybe in four and a half.

\section{Dreaming to get admission to engineering}

Prior to this research it was informally known that people in urban areas were familiar with and praised the UPRM's college of engineering excellence. Nearly all students participating in the focus groups confirmed that perception. For this reason, when a student shows good academic achievement it is likely that he or she would be instill the goal to study at the UPRM by his family and teachers. The majority of the participants knew about the existence of the UPRM when they were in high school, $86 \%$ of females and $100 \%$ of males stated that they had heard 
something about this university when they were in high school. Knowing the existence of this engineering school a priori was a very important factor in their decision to seek admission here. Prestige in Puerto Rican society and economic rewards are seen as a reason that motivates students to study here for some. These experiences are exemplified by the comment of a female student who said "My Math professor talked about the UPRM and that motivated me". Another good example was another female student who said: "They talked about the UPRM like if it was the most important thing on earth".

Gender did not carry any type of segregation when the matter was about discussing the possibility of entering the UPRM. Most opinions and perceptions of the parents of focus groups participants regarding university admissions were free of gender discrimination remarks. Even though many people did consider engineering as a male career, parents saw engineering as a possible option regardless of their child being a girl or a boy. In the case of female students, the role of the mom supporting the girl's choice was very important. One of the focus groups' facilitators said during the development of the questionnaire: "When I was a child my mom used to drive by the UPRM and stop the car in front of the UPRM's main gate just to tell me, when you grow up you are going to study here. Naturally when I grew up I thought nothing but to seek admission." Another student said: "My Dad was not really in agreement but my mom decided she would support me, so the whole family did." Furthermore, $67 \%$ of the females said that their parents did not pressure them to study Industrial Engineering; they applied and enrolled because they really wanted to. For female participants, their parents gave the opportunity to choose a career in whatever field they felt comfortable. They applauded their choice and it was a source of family pride. A decision to choose a career free of family pressures was a circumstance more prevalent among female participants than males. The majority of males said their parents put a lot of pressure to apply to engineering at UPRM. For $67 \%$ of the male participants the pressure coming from the family to study engineering was the main factor to seek admission.

\section{Self-efficacy beliefs}

Based on the discussion around the questions: What came to your mind when you completed your college application? Did you have any doubts about completing the application?, we could observe that women in the sample had in general more confidence than men about being capable of qualifying for admittance at the UPRM (i.e. in the Industrial Engineering (IE) Department.) $88.9 \%$ of the females were sure that they would be accepted in the IE department at the time of application, while only $33.3 \%$ of the male participants stated were confident of being accepted. Self-efficacy beliefs for these students while in high school were very high. Female students, in the same proportion as male students, all said that they believed they were good in math when they were in high school. Most females were sure of being accepted because of their good grades and scores in the college admission tests. For example, one of the female participants said: "Yes, I knew I was going to be accepted because I had good grades". Also, some of them mentioned that they knew that they were going to be admitted in the IE department because entering this department was their goal, which motivated them to prepare themselves for engineering while in high school (by taking advanced math classes). One of the female participants commented that she knew she was going to be admitted because she wanted to enter the UPRM so much that she 
prepared herself for that from a very early age. These females were as sure as male of their mathematical ability.

\section{Cultural biases and fear of discrimination}

We asked female participants to recall any second thoughts at the time of application to the UPRM, looking for biases that could have prevented these females to go ahead with their application process to the engineering school. We were expecting some cultural biases against engineering careers such as issues with the career chosen or the level of difficulty of the coursework, or emotional issues, such as family-related emotions due to separation given that the Puerto Rican family is a tight nucleus and parents expect the children to live with them until marriage. There were no prevailing themes in the answers. The female students that participated had a diversity of thoughts at the moment that they completed their college application. In general, thoughts fluctuated around factors that could affect them either positively or negatively after admission to the IE department. Some of these factors were: distance from home, time to complete (since engineering in PR is a 5 year program). Over a third of them (36\%) expressed they were hopeful of a better future since engineering is a well-paid career. Only $36 \%$ had some thoughts related to gender differentiation, but not necessarily gender discrimination and certainly not fear of discrimination or inadequacy. 32\% had thoughts regarding the potential discrimination they could be exposed to in industry, but always with a positive outlook of it being a challenge and not a barrier.

For example, one of the female participants said:

"I thought that I was going to be a professional. It is not easy to be a woman engineer. It is a challenge, you are competing to stand out in an area in which you are used to see only men, and I see this as a challenge."

Another one said:

"I though I was going to achieve my goal because I wanted to be an engineer...I wanted to be one and that is it. You complete the form quickly because you have the motivation of facing a challenge and you want to see if you are capable of achieving it."

We observed that attitude in most cases, these females had their goals well-defined and although some of them were afraid of suffering gender discrimination later in their careers, they saw this as a challenge and completed the application anyway.

The proportion of female students that did not have any doubt about applying to the IE department was the same as their male counterpart.

In the past, engineering careers were dominated by males in Puerto Rico, because of that we were expecting some discussions about facing stereotyping comments about women not being as good for technical jobs or jobs in the manufacturing industry. The experience of $50 \%$ of these females was that nobody expressed those types of comments to them, and did not face these types of stereotypes. In other words, they perceived society as considering females equally capable of doing as good engineering work as males are. However, the other $50 \%$ said that they 
did hear negative comments about women being engineers but they decided to study IE anyway and demonstrate that these comments didn't affect their decision.

\section{Lookout to the future}

All the participants, females and males, were sure that they will eventually complete their coursework and earn the IE bachelors degree. However, institutional statistics show that in reality more women than men graduate from the IE department. The latest statistics of the UPRM indicate that of every 10 graduates 6 are female and 4 are male while enrollment numbers show roughly half of the new enrollees being female. Attrition is higher in males than females.

All of the females participating had confidence in their ability to enter the UPRM but after entering they were also sure about eventually completing the coursework and getting their engineering diplomas. There was no difference between female participants and male participants regarding their prediction of the time (in years) they though it will take them to complete their bachelors degree in IE. All female participants said in equal proportions to their male counterparts that they expected to graduate between 5 and 7 years with no noticeable difference across other control characteristics or different groups.

\section{Work preferences}

The women that participated in the focus groups were not afraid of entering an area that is dominated by men or seen as a "men's job". One of the characteristics of the IE curriculum at the UPRM is that the academic preparation is wide enough to provide students with the tools to work in a great variety of areas. Industrial engineers can work at any company that offers a product or a service. Some engineers work in administrative areas as analysts, like those involved with economic analysis, but the majority of careers in Puerto Rico are related to manufacturing. IE graduates work directly with machinery and line workers inside factories in areas such as quality control and production planning. Most of the female students interviewed (86\%) wanted to work closely with line workers or machineries and only $14 \%$ were hoping to land a job in a more administrative (behind a desk and a computer) area. Moreover, when female participants were asked where they see themselves working in ten years, most of them answered: in $a$ manufacturing company. One of the female students said: "I see myself involved in projects, or more supervisory tasks, not in an office in front of a computer". Most of these females felt capable of working in any area of IE though.

\section{Conclusions}

We initiated this research project looking for the Psycho-social characteristics of female engineering students in Puerto Rico in an attempt to explain the fact that an equal number were entering IE and 39\% were graduating from all engineering programs at the UPRM. Even more surprising, a larger number of female than male students end up graduating in IE in particular. We hypothesized that the fact that female high school students want to study engineering in equal numbers than males can be attributed in part to social and psychological factors. Despite a chauvinistic Caribbean culture that prevails in many aspects, our study confirms that society in 
Puerto Rico sees women as capable to be leaders, to make decisions and to offer a good service as males. Furthermore, observation of society's roles in Puerto Rico demonstrates that female roles in the family are stronger than males and the support and incentive received by girls from their mothers to further their education is crucial. An example of this is the fact that the island chose a woman as governor in 2000. A fact that has occurred in many instances in other states, but that demonstrates that contrary to popular belief, Puerto Rican society trust women as leaders.

As we can see women are strongly represented in the working society, as they are in the student society, in PR there are 553,000 employed women. This represents forty-four per cent of the working society of PR. 130,000 of those not working are studying. Women's roles have fewer limitations than in other places. The educational level of the women in the employment market is higher than that of men ${ }^{32}$. This last fact suggests that women in Puerto Rico are in general more qualified than men to work.

The main observations of our study were:

- The girls that entered the IE program had very high self-efficacy beliefs at the time of application. They were encouraged by their teachers to consider engineering as a career and they thought they were especially good in math.

- Women in PR are given the liberty to choose the career without gender discrimination versus other women that experience gender stereotyping at home ${ }^{33}$. Many girls are motivated by their parents (particularly the Mom) to study engineering and seek financial independence. This happens regardless of the educational level the moms themselves achieve ( $45 \%$ of these girls would be considered below the poverty level in the United States).

- Women in PR consider competition as a challenge and as an opportunity to succeed while other women do not like to compete or to be challenged because of the anxiety it can cause them $^{34}$.

- Many women do not study engineering because of their cultural influences and stereotyping caused by books and media ${ }^{35,36}$. However, in Puerto Rico cultural influences serve as a buffer against stereotyping. Puerto Ricans consider women capable of executing any role. The females observed did not consider stereotyping as a barrier; on the contrary they considered it a challenge and an opportunity to demonstrate how capable they can be.

To finalize, we want to summarize what we believe are the psycho-social characteristics found in our study that we think promote the participation of more women in engineering in Puerto Rico than in other places:

\section{Psychological Characteristics}

Strong personalities, high self-efficacy beliefs while in High School, self-reliance and optimistic look-out at the future. Girls feel comfortable around males and are ready to express their views.

\section{Societal Characteristics}

The engineering career and the engineering school are well-respected institutions. Engineering is a desirable career for most families regardless of social or economic status or the educational level achieved by the parents. The mom's opinion is highly respected at home. High School 
teachers motivate good students (both males and females) to seek admission in engineering. Students are familiar with the engineering option from a very early age. Parents support of girl's choices and demonstrate pride of a daughter studying engineering. Role models (women in engineering) are known by most.

Attracting more girls into engineering in the US perhaps requires institutions to create programs aimed at developing the same self-efficacy, confidence and independence of these girls, or to recreate the societal, personal and family beliefs and support received by Puerto Rican girls. As this is only an exploratory study, more research is necessary in that direction.

\section{References}

1. Determined to open doors, Introduce a Girl to Engineering Day takes on new urgency. Engineers Week Web Site, 2005 Nov 10, 2005 [cited 2007 Jan 15]; Available from:http://www.eweek.org/2002/News/Eweek/2005_girdlayupdate.shtml.

2. Extraordinary Women Engineers Project (EWEP) study. 2005, WGBH Educational Foundation.

3. ASEE, Data bytes, in Prism 2005

4. ASEE, Profiles of Engineering and Engineering Technology Colleges. 2004.

5. (OII), I.R.O., Graduation and Enrollment by Gender 1991-2006. 2006, University of Puerto Rico at Mayaguez.

6. Vela, Charles E, Obstacles Impacting Latino Representation in Science and Engineering, On line. Center for the Advancement of Hispanics in Science and Engineering Education, CASHEE : http://www.cahsee.org/about/obstacles.asp

7. Picó, M.B., Island of Technology, in Hispanic Engineer and Information Technology ONLINE. 2003.

8. Gonzales-Barreto, D., Gonzales-Quevedo, A., Applicant's Profile Study for Improving Undergraduate Enrollment in the Engineering School

of the University of Puerto Rico at Mayagüez. American Society of Engineering Education. 2006.

9. Ref. 5

10. Ref. 8

11. Van Aken.,E..,Watford B., Medina-Borja A. The Use of Focus Groups for Minority Engineering Program Assessment, Journal of Engineering Education, July 1999.

12. Krueger, Richard A., Focus Groups: A Practical Guide for Applied Research, SAGE Publications Inc., Thousand Oaks, CA, 1994.

13. Amer. Assoc, o.U.W., Shortchanging Girls, Shortchanging America, in AAUW Publications. 1991: Washington, D.C.

14. Levenson, N., Educational pipeline issues for women. Comput. Res. News, 1990. October: p. 11-13.

15. Melymuka, K., If Girls Don't Get IT, IT Won't Get Girls, in Computer World. 2001.

16. Gilligan, C., In a Different Voice. 1982, Cambridge, MA: Harvard University Press.

17. Belenky, M.F., et al., Women's Ways of Knowing. 1986, Basic Books: New York. p. 190214. 
18. Engineering University Enrollment Statistics, Ontario Ministry of Education and Training, November 27, 1997.

19. CBC News, More women study engineering, math, science 2003: Canada.

20. Ref. 19

21. Steele, Claude M., "A Threat in the Air: How Stereotypes Shape Intellectual Identity and Performance," American Psychologist, LII (1997), 613 - 629

22. Brush, S.G., "Women in Science and Engineering", American Scientists, vol. 79,1991, pp. 404-419

23. Do Women Shy Away From Competition? Do Men Complete Too Much? MurielNiederle, Lise Vesterlund. Working Paper 11474. http://www.nber.org/papers/w. National Bureau of Economic Research.

24. S. Tobias, "Women in Science - Women and Science", JCST, March 1992, pp. 276-278.

25. Society of Women Engineers Web site. URL. http://www.stanford.edu/dept/news/pr/2006/prswe-061406.htm, assessed January 5, 2007.

26. Seymour, E., and N.M. Hewitt, Talking About Leaving. Factors Contributing To High Attrition Rates Among Science, Mathematics, \& Engineering Undergraduate Majors: Final Report To The Alfred P. Sloan Foundation On An Ethnographic Inquiry At Seven Institutions, Bureau of Sociological Research, University of Colorado, Boulder, 1994, p. 1.

27. Ref. 23

28. NSERC/Nortel Joint Chair for Women in Science and Engineering in Ontario Web Site: http://www.carleton.ca/wise/natstats.htm

29. Ref. 18

30. Ref 19

31. Ref 19

32. Manuel Lobato Vico, N.F., Víctor Curi, Proyecto www.tendenciaspr.com Programa Interfacultativo y Interdisciplinario de Estudios de la Mujer y el Género, Decanato de Estudios Graduados e Investigación (DEGI), la Facultad de Estudios Generales y su Departamento de Ciencias Sociales: Universidad de Puerto Rico, Recinto de Río Piedras.

33. M. Frize, 1992, "More Than Just Numbers", Report of the Canadian Committee on Women in Engineering.

34. Ref. 21

35. Ref. 33

36. Ref. 22 